\title{
O GROTESCO COMO CRÍTICA SOCIAL AO NAZISMO NO FILME $O$ TAMBOR, DE VOLKER SCHLONDORFF
}

\author{
Carla Lavorati ${ }^{1}$ \\ Maristela Scremin Valério ${ }^{2}$
}

RESUMO: O objetivo do trabalho é analisar no filme O Tambor como a representação do grotesco é um mote para a composição de sentidos que interrogam, de modo geral, a violência e a alienação. Na cidade de Danzig, nos anos de 1920, o personagem protagonista, Oskar, decide parar de crescer; e essa condição de adulto infantilizado marca a narrativa com cenas grotescas e mesmo de tom fantástico. Ocorre, portanto, relações indissociáveis entre história coletiva do período entre guerras e o espaço privado no qual se desenrolam a vida íntima dos personagens. O microcosmo da vida familiar de Oskar e também a comunidade de Danzig podem ser incorporados a problemática maior: a história da ascensão e queda do nazismo. Assim, observamos como a crítica social no filme associa-se a representações de imagens que exploram o absurdo da guerra e do totalitarismo.

Palavras-chave: $O$ Tambor, Cinema; violência; nazismo.

Abstract: The objective is to analyze on the film The Tin Drum how the grotesque's representation is a motto for composition of meanings that question the alienation and violence in general. In Danzig city, on 1920s, the main character Oskar decides to stop growing, this condition of infantilized adult marks the narrative with grotesque scenes sand fantastic mode. Therefore, inseparable relationships happen between collective history of inter war period and private space on which unfold intimate life of the characters. Thus, the Oscar's family life microcosm and Danzig community can be in corporate into a biggest problem: the rise and fall of the Nazism. Thus, we can note that the movie's social criticism is referring to representations of images which explore war's absurdity and totalitarianism.

Keywords: O Tambor, Cinema; violence; Nazism.

1 Doutoranda em Estudos Literários no Programa de Pós-Graduação em Letras na UFSM. Bolsista Capes, participante

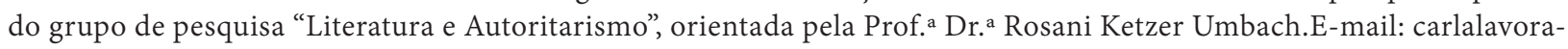
ti@gmail.com

2 Atualmente é professora no curso de Comunicação- Social- Jornalismo, na Unicentro e doutoranda em Estudo Literários pela Universidade Estadual de Maringá. Possui graduação em Comunicação Social-Jornalismo pela Universidade Estadual do Centro-Oeste (2007), graduação em Letras Português e suas Literaturas pela Universidade Estadual do Centro-Oeste (2008) e mestrado em Letras pela Universidade Estadual do Centro-Oeste (2014). E-mail: maristelasv@ gmail.com 
Coisa curiosa e verdadeiramente digna de atenção a introdução desse elemento inapreensível do belo até nas obras destinadas a representar ao homem sua própria feiura moral e física! E, coisa não menos misteriosa, esse espetáculo lamentável excitar nele uma hilaridade imortal e incorrigivel. Charles Baudelaire - Da essência do riso

\section{INTRODUÇÃO}

O diretor Volker Schlondorff, responsável pelo filme O Tambor (1979) ${ }^{3}$ - adaptação do romance do alemão Gunter Grass ${ }^{4}$, publicado em 1959 - faz parte de um grupo de cineastas que promoveram uma renovação no cinema alemão das décadas de 60 e 70 do século XX. A cinematografia alemã passa a se posicionar criticamente no período do pós-guerra, com representações que problematizam a história coletiva da Europa; principalmente as guerras do século XX e a ascensão de regimes totalitários. Passa a ser recorrente temas que exploram angústias existenciais, o passado violento, racista e preconceituoso. Nesse cenário, o filme $O$ Tambor é um marco do cinema alemão, sendo ao mesmo tempo lírico, tragicômico e repulsivo.

Oskar (David Bennent), protagonista do filme, cresce no período entre guerras. Vive no contexto da ascensão e queda do Nazismo alemão. A história se desenvolve na cidade de Danzig5, que foi uma espécie de "cidade livre" criada após o fim da Primeira Guerra Mundial, a partir do Tratado de Versalhes (1919). A cidade, porto comercial, estava sob o controle dos poloneses, enquanto a população predominante se mantinha alemã. Nesse cenário, a convivência entre os diferentes povos (caucasianos, poloneses e alemães) é tensionada pela ocupação nazista da cidade em 1939 e que se estendeu até 1945, quando ocorre a queda do regime nazista e a retomada do controle da região pelos poloneses. Desse modo, numa espécie de epopeia familiar que atravessa fatos históricos importantes, o filme representa o drama de uma criança vivendo no contexto de ascensão do nazismo.

Cena de abertura do filme. Ano de 1899, uma imagem em plano geral de uma lavoura de batatas, na região da Cassúbia, norte da Polônia; representando um período anterior ao nascimento do protagonista e narrador Oskar. Território dos povos cassubianos, esse é o local onde acontece o primeiro encontro entre os personagens Anna Bronski (Tina Engel) e Joseph Koljachek (Roland Teubner), avô e a avó do protagonista. A sequência da primei-

3 Ganhador do Oscar de Melhor Filme Estrangeiro e da Palma de Ouro no Festival de Cannes, "O Tambor" foi um filme polêmico e proibido por alguns países - Canadá (província de Ontario) e nos EUA (Oklahoma City) - por ser considerado agressivo, com cenas "fortes" de sexualidade entre menores. O roteiro de O tambor teve a participação de Schlndorff, JeanClaude Carrière, Gunter Grass e Franz Seitz.

4 Günter Wilhelm Grass, poeta, romancista, dramaturgo, artista plástico e intelectual; ganhador do prêmio Nobel de Literatura (1999), prêmio Georg Buchener (1965) e prêmio Princesa das Astúrias (1999). Seu romance Die Blechtrommelé analisado por alguns críticos como narrativa de traços autobiográficos. Grass, nascido em Dazing em 1927, se envolveu com as forças armadas da Alemanha nazista.

5 A Polônia recebeu plenos direitos para desenvolver e manter o transporte, comunicação e instalações portuárias na cidade. A Cidade Livre foi criada a fim de dar a Polônia acesso a um porto bem dimensionado, enquanto a população da cidade era de maioria alemã, mas tinha uma minoria significativa de polacos. A população alemã, ressentida da separação da Alemanha, submetia a minoria polaca à discriminação étnica. Isso aconteceu especialmente após o Partido Nazista assumir o controle político em 1935. 
ra cena monstra a fuga de Koljachek - incendiário polonês - da polícia do II Reich alemã. Quem narra esse primeiro momento do filme é Oskar, que regressa a um período anterior a sua existência e conta a história famíliar pregressa, narrando o encontro dos avôs e o posterior nascimento de sua mãe, Agnes (Angela Winkler).

Agnes, mãe de Oskar, tem um envolvimento afetivo com o primo Jan Bronski (Daniel Olbrychski) e mantém esse relacionamento mesmo depois de casada com Alfred Matzerath (Mario Adorf); o primeiro sendo representante do povo polonês e o segundo representante do povo alemão. Esse triângulo amoroso representa, de certo modo, a proximidade entre caussubianos, poloneses e alemães que povoavam a mesma região, como também as ambivalência das relações sociais que o território de Dazing foi palco, principalmente no período das guerras e disputas territoriais.

O nascimento de Oskar é narrado por sua própria perspectiva, com um jogo de imagens que representam o interior do útero materno e segue para passagens posteriores que descrevem as primeiras impressões que Oskar tem do mundo externo, da figura materna e paterna. A cena do nascimento evoca um cenário grotesco, que está presente tanto nas imagens sanguinolentas do interior do útero como na escolha de manter o mesmo ator, David Bennent, que atuará do restante do filme, para a representação de um recém-nascido. Ou seja, o mesmo ator irá representar o personagem Oskar em todo o percurso de sua vida, que vai do nascimento aos vinte anos de idade. Esse personagem, que no decorrer de toda a narrativa mantém-se junto a um tambor de brinquedo que toca sempre que se sente incomodado. Oskar, além de parar de crescer aos três anos, também adquire o "dom", inexplicável, de quebrar superfícies de vidro com o som agudo de sua voz. Na sequência abaixo apresentamos as imagens referentes ao nascimento de Oskar, seu tambor e o poder fantástico de estilhaçar vidros:

Sequência 1:cenas do filme O Tambor. Nascimento de Oskar, o tamborileiro e seu poder de quebrar vidros. (Tempos respectivamente:12'08/41'27/41'35)
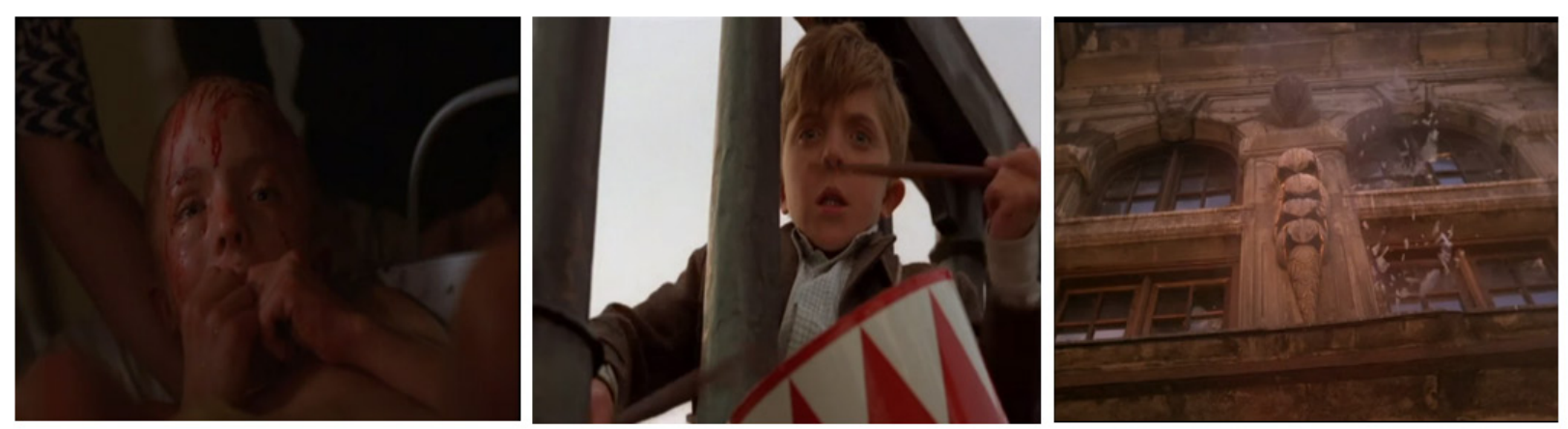

Fonte: Die Blechtrommel, Volker Schlondorff, 1979. P\&b, 142 min.

O tambor e a voz potente de Oskar são simbologias que contribuem com o tom fantástico de algumas cenas como: a quebra dos vidros de grandes prédios da cidade, após o tamborileiro, com sentimentos de raiva, descontentamento, indignação, ao perceber mais um encontro às escondidas de sua mãe com o primo Jan Bronski. O menino soube até a torre de uma igreja e de lá toca seu brinquedo infantil com tamanha força e convicção, enquanto 
solta um grito agudo e interminável, que as vidraças dos grandes edifícios da cidade se estilhaçam e vão ao chão como consequências do inexplicável poder de Oskar de desestruturar superfícies estáveis.

Desse modo, exposto brevemente o enredo do nosso objeto de análise, defendemos que no filme $O$ Tambor existe a representação crítica de um período histórico traumático e que isso é elaborado a partir de recursos do grotesco. Volker Schlondorff como Guter Grass criaram - um em tinta e papel e o outro em imagens e cores -um personagem atemporal, que na sua bizarrice infantil e no grotesco e mesmo fantástico das situações que vivencia, faz "ressoar" sentidos sobre absurdos do real. E essa atemporalidade se deve, principalmente, pelas situações absurdas que problematiza e pelas contradições que desvela da alma humana, trazendo à tona na história familiar dos Matzerath, a violência e os paradoxos de uma história maior, a História da Civilização como uma história da barbárie, tal qual refere-se Walter Benjamin (2012).

\section{O GROTESCO E A CRÍTICA SOCIAL: INCURSÕES PELA HISTÓRIA E PELA MEMÓRIA}

Oskar resolve parar de crescer aos três anos de idade, após observar dentro de casa os jogos de traição entre a mãe, o tio e o pai e considerar o mundo dos adultos como dissimulado e hipócrita. Para dar cabo ao seu intento, resolve se jogar de uma escada para provocar um acidente que o fizesse parar de crescer. O filme não apresenta explicações sobre o acontecimento extraordinário de Oskar ter parado de crescer, apenas, após o acidente, a realidade é dada: Oskar será um adulto em corpo de criança. No decorrer do filme, portanto, esse fato será motim para cenas estranhas e até mesmo grotescas de sua vida íntima, já que suas experiências na vida adulta acontecem em um corpo sempre infantilizado, de um menino de três anos. Assim veremos o envolvimento sexual de Oscar com duas personagens de modo explícito: Maria Matzerath (Katharina Thalbach) sua babá e depois madrasta e Roswitha (Mariella Oliveri), uma anã da companhia de circo a qual se junta no decorrer da trama.

Para além dos dramas individuais e dos jogos sexuais que são relegadas ao ambiente privado, temos também a representação da história coletiva da região norte da Polônia, com cenas do movimento nazista que se espalhava pela Europa e das consequências violentas do regime autoritário. Assim, no filme são representadas marchas nazistas, comícios e discursos pró-Hitler em momentos de ascensão e controle da cidade de Danzig até representações sobre a queda nazista e a ocupação russa.

Dessa forma, podemos considerar que a representação do contexto da guerra e do nazismos e dá pela ótica de um narrador dúbio, Oskar, que condensa tanto sentimentos de maldade, cinismo e vingança (confessando sua intenção em provocar tanto a morte de Jan Bronski como de Alfred Matzerath) como também expressões de inocência infantil e amabilidade; o que provoca possibilidades para que a construção narrativa perpasse o absurdo e provoque no telespectador tanto o riso como a repulsa.

Nesse sentido, são muitos os momentos no filme nos quais ocorrem situações de um 
tom grotesco e cômico, como a cena da anã circense Roswitha (namorada de Oskar) que ao fugir dos bombardeios da guerra, por um lapso de capricho, resolve parar para tomar um café, e nesse intervalo de descuido e sandice, ela é alvo de uma bomba e explode, pouco antes de tomar o último gole de seu café. Essa cena, tal qual outros do filme, são típicas do entrelaçamento entre as vertentes do trágico e do cômico no que se refere a violência desumana e absurda dos conflitos de guerra.

O fato de Oscar não crescer pode ser compreendido como negação da realidade, no qual o personagem prefere viver uma eterna infância para evitar os problemas e responsabilidades da vida adulta. Oskar é uma espécie de Peter Pan e é nisso que mora o seu caráter grotesco, visto que é um adulto com corpo de criança, vivendo em um ambiente pouco propício para aquilo. Dessa forma, permanecer na infância é permanecer em um espaço de alteridade, protegido e alienado da realidade.

Oskar, no decorrer do filme, se torna um artista circense. Um tamborileiro que usa seu tambor e seu grito como atração de uma companhia circense liderada por um anão. Anões são relacionados classicamente à ideia do corpo grotesco e por isso "personificam as manifestações do inconsciente [...] são considerados como irresponsáveis e invulneráveis, mas escutados com um sorriso" (CHEVALIER; GHEERBRANT, 2015, p.49) e, nesse caso, os anões ficam simbolicamente relacionados ao divertimento e estão na posição contrária à seriedade do mundo dos adultos. Assim, no filme, a companhia de entretenimento formada por anões está, de certa forma, protegida da guerra por sua anormalidade, que é explorada para a diversão dos altos escalões do exército nazista.

Em uma das cenas, a trupe faz um piquenique a céu aberto, vivendo um momento de idílio enquanto ataques aéreos bombardeiam o entorno. Dessa forma, podemos perceber que além da infância o espaço da anormalidade representada pelo circo de anões também fica protegida da guerra, visto que, por não serem considerados pessoas normais, os anões circulam pelos espaço de guerra dominado pelos nazistas. Porém, mesmo vivendo momentos de alienação, a trupe não consegue fugir totalmente da guerra, pois Roswitha, a namorada anã de Oskar, acaba sendo atingida por uma bomba. Nesse momento, começa o processo de transformação de Oskar, que vai perdendo a sua "inocência” inicial e entrando no universo adulto. Pode-se perceber isso na cena que mostra o retorno de Oskar para casa e na mudança em sua fisionomia, assim como na forma como passa a se comportar a partir desse momento.

Oskar configura-se como grotesco justamente porque desafia a normalidade duplamente: a partir de seu corpo anormal e pelo contexto grotesco da guerra. Por outro lado, a maneira mais fácil de enfrentar o horror, adotada pelo personagem é colocando-se à margem. A infância é um período de marginalidade do ser humano, visto que a criança é isenta de responsabilidades perante seus atos.

A forma que personagem encontra de fazer essa transição entre o seu mundo marginal e o mundo real é através do tambor, que, assim como significa a tomada de voz de Oskar frente ao mundo, também é dissonante e, por isso, uma forma de resistência. No Dicionário de Símbolos, o tambor "é um símbolo da arma psicológica que desfaz internamente toda a resistência do inimigo [...] associado ao simbolismo da caverna, da grota, da matriz" (CHEVALIER, GHEERBRANT, 2015, p.861-862). Dessa forma, o apego ao brinquedo é uma 
forma de mostrar-se ao mundo e, ao mesmo tempo, proteger-se dele. Tanto que, quando Oskar decide crescer, sua primeira atitude é jogar o tambor na cova onde o pai estava sendo sepultado.

O tambor é também o que dita o ritmo à narrativa e à vida de Oskar. Ele utiliza o instrumento como forma de se comunicar, mas também de fugir da realidade. Como na cena em que há um comício de recepção do líder nazista na cidade de Danzig. Em meio ao horror da doutrinação nazista ao povo, Oskar, utiliza o tambor como um elemento dissonante, que atrapalha o ritmo ensaiado da banda militar e transforma o ritmo marcado em uma valsa. A cena de um discurso sério nazista, com direito a marcha musical e recepção pomposa do palestrante, transforma-se, depois da intromissão de Oskar, numa dança coletiva de valsa, incorporando a sequência da ação um tom de fantástico e irônico ao encontro político do partido nazista. Sendo assim, o tambor simboliza uma voz de resistência à realidade, personificada na imagem do instrumento e da criança.

No filme há um clima que provoca repulsa no espectador. Kayser (1986), afirma que ao mesmo tempo em que o grotesco seduz, ele causa desconforto, o que é bem perceptível no filme $O$ Tambor, pois a narrativa se constrói sob um clima do grotesco, como nas cenas de sexualidade infantil.

Sequência 2: Primeiras experiências sexuais de Oskar com sua babá Maria. (Tempo das cenas respectivamente: 1'42'46/ 1'46'14/ e 1'45'43/). Cena em que Oskar vê se pai fazendo sexo com Maria. (Tempos das cenas respectivamente: 1'47'29/1'47'13) e a cena de Oskar com sua namorada anã, Roswitha. (Tempo da cena:2’06’20)
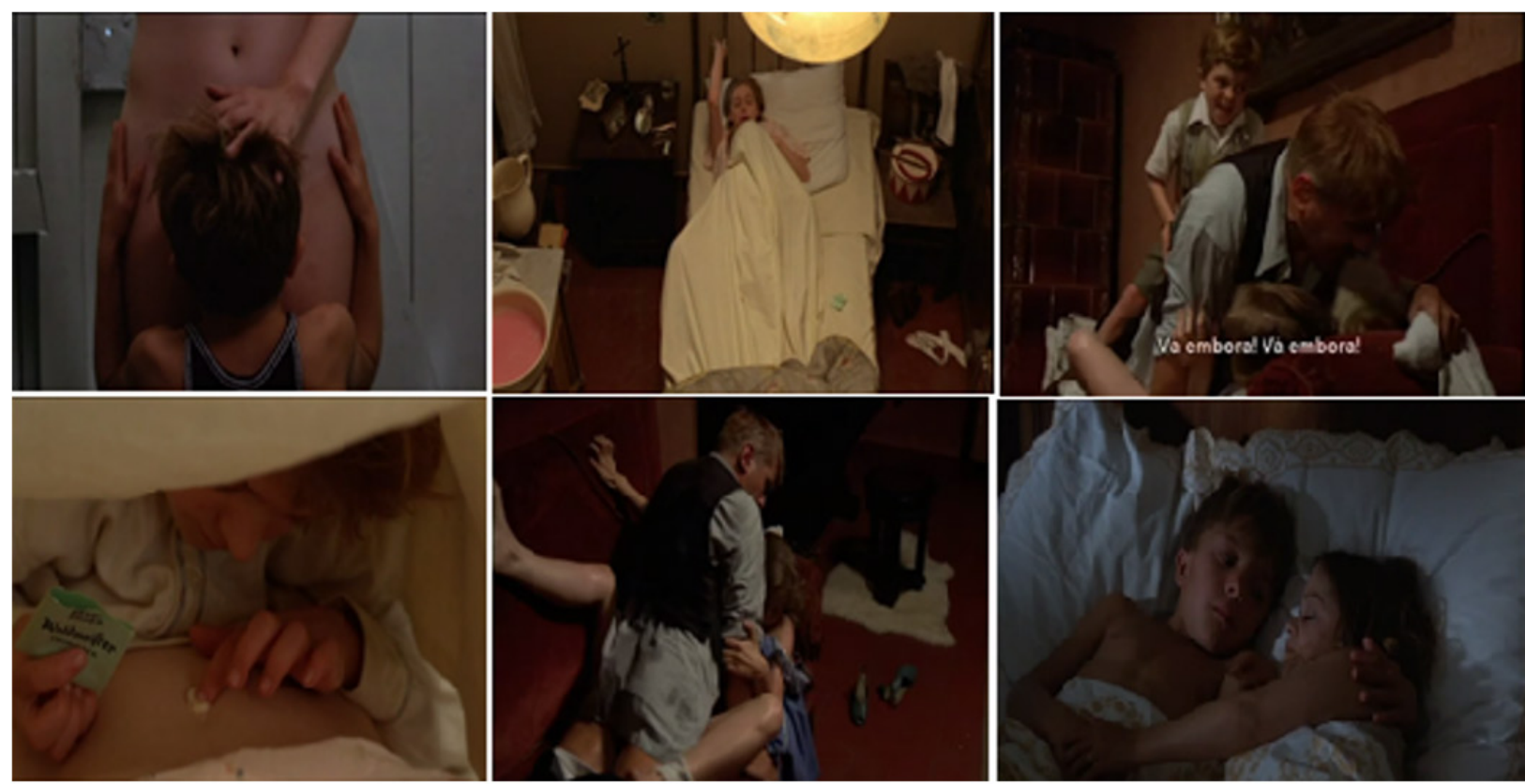

Fonte: Die Blechtrommel, Volker Schlondorff, 1979. P\&b, 142 min.

Assim, reforçamos o caráter grotesco da representação fílmica, pois, de acordo com Sodré e Paiva (2002), o termo grotesco define-se por tudo aquilo que pode provocar riso, horror, espanto, repulsa (SODRÉ; PAIVA, 2002, p.17). Já para Silva Santos (2009), o grotesco 
pode ser considerado "um outro olhar" sobre o real, explorando extratos suprarracionais e inconscientes (SANTOS, 2009). Grotesco é tudo aquilo que provoca sensações de estranheza para o espectador, provocando reações inusitadas e por vezes opostas, como o riso, o medo e a incerteza. De acordo com Santos (2009), no grotesco figura o mistério e o excêntrico, por isso pode ser considerado como uma estética do outro, imanando uma alteridade que se mostra incompreensível, incerta e hostil ao senso comum.

Suas origens estão nos outros mundos, representados pela fantasia, pelo sonho e pelo sobrenatural; na outra cultura, expressa pelos costumes populares em relação ao modus vivendi oficial; nos outros reinos da vida, manifestados pelo bestialógico; nos outros estados de consciência entrevistos nos surtos de loucura e nas manifestações do in consciente e no outro eu que toma forma nos simulacros, nos autômatos, nos monstros e nos duplos (SANTOS, 2009, p.138).

Wolfgang Kayser (2003) afirma que "o grotesco é o nosso mundo e não é" (KAYSER, 2003, p.139). Sendo assim, o horror se mescla ao riso, produzindo uma experiência alheia àquilo que conhecemos. Para ser considerado grotesco, o fato precisa ser considerado como tal por alguém. Dessa forma, verifica-se que o grotesco não existe por si só, mas em relação a um grupo normativo, o que reitera mais uma vez a questão da alteridade. Ainda para Kayser (2003) o grotesco está contido nesse entre lugar entre o mundo real e aquele imaginado, que provoca uma mescla de horror e humor.

Ainda sobre o fato do filme apresentar como pano de fundo o contexto histórico da tomada da cidade de Dazing pelos nazistas, defendemos que a representação simbólica em O Tambor tem a função social de mobilizar a memória coletiva sobre as Grandes Guerras e o nazismo. Nesse sentido, no filme O Tambor são potencializados manifestações da memória de historicidade. $\mathrm{E}$, assim, podemos dizer que é através da memória que é estabelecido a condição de legibilidade do dizer, já que as palavras não carregam um sentido em si, mas significam pela relação com uma anterioridade que também as constituem. Portanto, as imagens representam um papel importante na circulação, complementação e cristalização de sentidos e de valores em relação aos grandes catástrofes do século XX. Por isso, a memória é tanto um espaço simbólico, de luta pelo controle do discurso e do saber, como espaço fronteiriço, de cruzamento entre individual e coletivo. Portanto, além dos mecanismos individuais, ela é acionada por diferentes marcas históricas e coletivas, conforme Pollak (1992), ela é "[...] um elemento constituinte do sentimento de identidade, tanto individual, como coletivo, na medida em que ela é também um fator extremamente importante do sentimento de unidade e coerência de uma pessoa, ou grupo na reconstituição de si" (POLLAK, 1992 , p. 205). Nesse sentido, as imagens que representam a ascensão do movimento nazista em Dazing e sua posterior derrocada, pertencem a uma dinâmica da memória que luta contra o esquecimento e repetição do horror. 
Sequência 3:Comício público do partido nazista na cidade de Dazing. (Tempo das cenas respectivamente: 52'32/53'31/56'43)
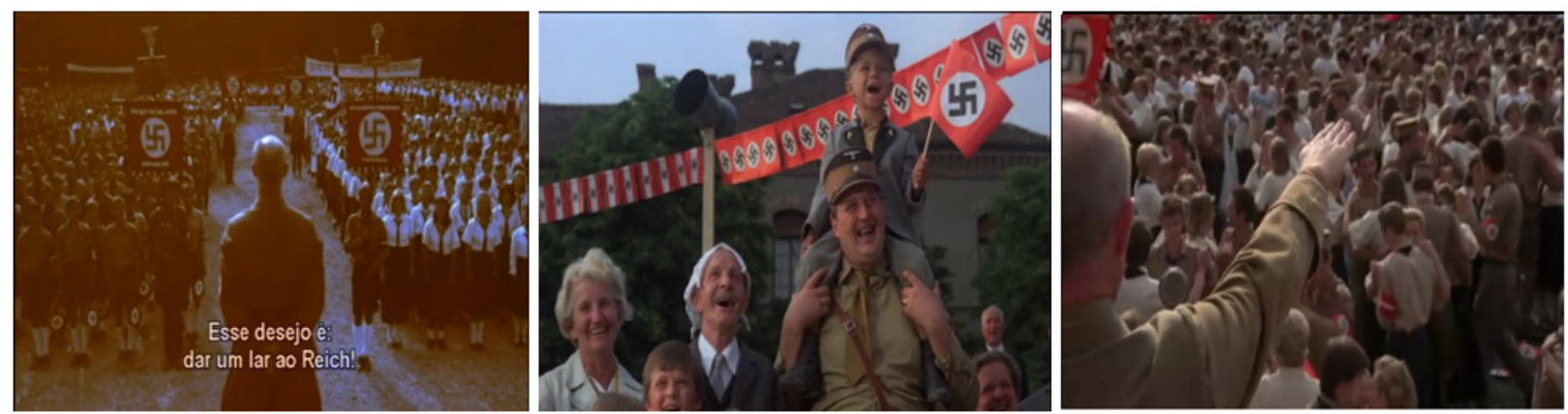

Fonte: Die Blechtrommel, VolkerSchlondorff, 1979. P\&b, 142 min.

A memória é, portanto, um fato social e de significação. E as imagens, nesse sentido, também são atravessadas por ela, recuperando sentidos e (re) significando-os pelas relações que estabelece com a exterioridade. Portanto, as imagens também funcionam como dispositivos de memória, pois carregam informações e encaminham o sentido para certa direção.

Sequência 4: Envolvimento de Oskar com a companhia de animação comandada por um anão. (Tempo das cenas respectivamente:1'58'25/2'04'52/ 2'05'18/2'10'24)
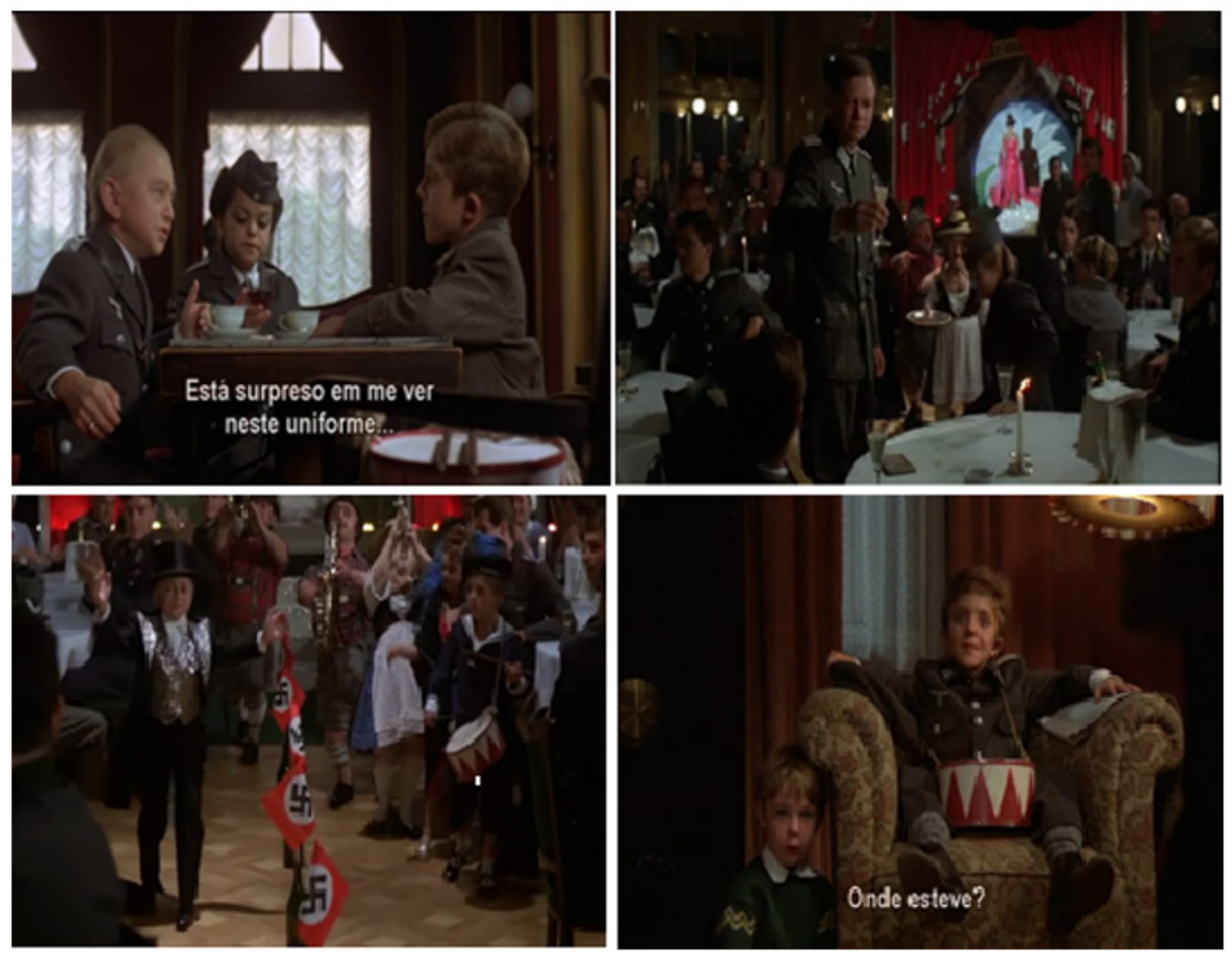

Fonte: Die Blechtrommel, VolkerSchlondorff, 1979. P\&b, 142 min. 
E, dessa forma, mesmo apresentando uma historicidade datada, o filme O tambor consegue se posicionar no rool dos filmes dos filmes atemporais, pois as escolhas da adaptação fílmica do romance de Grass preservam a potencialidade - presente nas grandes expressões artísticas - de inquietar e fazer vacilar as convicções do expectador, ao conseguir manter em tensão, nas entrelinhas das imagens e palavras, questionamentos que se voltam para o grotesco da própria existência; para os modos e práticas sociais que nós forjamos, enquanto seres históricos e culturais, que perpetuam a violência e a lógica da destruição. O grotesco, nesse sentido, está presente no sentimento do estranho como algo que nos é familiar e que se comporta como uma dimensão outra de nós mesmos que é preciso evitar que venha à tona. Assim, a representação fílmica de $O$ Tambor tem o mérito de produzir o estranhamento no expectador, contribuindo para questionamentos sobre a culpa coletiva da manutenção da barbárie, o que o torna um clássico do cinema alemão do século XX.

\section{CONSIDERAÇÕES FINAIS}

O filme $O$ tambor, portanto, mantém em sua dinâmica representativa incursões pelo grotesco e pelo fantástico e com isso consegue se posicionar de modo crítico (e mesmo irônico) diante de questões como guerra, poder e violência, conseguindo manter seu potencial de interrogação diante da cultura e da barbárie. O personagem Oskar, e a complexidade que lhe constitui (ora menino, ora adulto; ora anjo, ora demônio; ora consciente, ora alienado), condensam a própria contradição da existência humana e as diversificadas limitações e fragilidades de nossa relação com o mundo, com o outro. E, nesse sentido, em O tambor somos colocados frente a frente com a realidade, mas um frente a frente que só é possível a partir do movimento de desvio que a arte promove, um deslocar do que é naturalizado pela cultura como essência, para que se descortine a convenção, e mesmo que por apenas um momento, uma nesga de verdade se apresente.

\section{REFERÊNCIAS}

BENJAMIN, Walter. Sobre o conceito da história. In: Magia e técnica, arte e política: ensaios sobre literatura e história da cultura. São Paulo: Brasiliense, 2012.

CHEVAliER, J; GHEERBRANT, A. Dicionário de Símbolos: Mitos, sonhos, costumes, gestos, formas, figuras, cores, números. Editora Jose Olympio, 26ª Ed. 2015

GAGNEBIN, Janine. Verdade e Memória do Passado. Projeto História. São Paulo, n 17, 1998, p. 213221.

POLLAK, Michael. Memória e Identidade Social. Estudos Históricos. Rio de Janeiro, vol. 5, n 10, 1992, p. 200-212. 
SANTOS, Fabiano Rodrigo da Silva. Lira dissonante: considerações sobre aspectos do grotesco na poesia de Bernardo Guimarães e Cruz e Sousa. São Paulo: Cultura Acadêmica, 2009.

SODRÉ, Muniz e PAIVA, Raquel. O império do grotesco. Rio de Janeiro, Mauad, 2002.

Recebido em 08 de agosto de 2016

Aceito em 15 de fevereiro de 2017 